\title{
La agenda política sobre migraciones en América del sur: el caso de la Argentina
}

Eduardo E. Domenech

\section{(2) OpenEdition \\ 12 Journals}

Edición electrónica

URL: https://journals.openedition.org/remi/3611

DOI: $10.4000 /$ remi.3611

ISSN: $1777-5418$

Editor

Université de Poitiers

\section{Edición impresa}

Fecha de publicación: 30 junio 2007

Paginación: 71-94

ISBN: 978-2-911627-44-6

ISSN: 0765-0752

\section{Referencia electrónica}

Eduardo E. Domenech, «La agenda política sobre migraciones en América del sur: el caso de la Argentina», Revue européenne des migrations internationales [En línea], vol. $23-n^{\circ} 1$ | 2007, Publicado el 30 junio 2010, consultado el 15 abril 2022. URL: http://journals.openedition.org/remi/3611 ; DOI: https://doi.org/10.4000/remi.3611

Este documento fue generado automáticamente el 15 abril 2022.

(C) Université de Poitiers 


\title{
La agenda política sobre migraciones en América del sur: el caso de la Argentina
}

\author{
Eduardo E. Domenech
}

1 En la última década del siglo XX, después que recibieran un tratamiento meramente coyuntural, las migraciones internacionales se han constituido en una de las principales preocupaciones de la agenda mundial ${ }^{1}$. Su aparición en las agendas ${ }^{2}$ de trabajo de numerosos actores sociales, desde organismos internacionales e instituciones estatales hasta organizaciones no gubernamentales y redes de asociaciones de migrantes, refleja la articulación cada vez mayor entre los espacios nacional, regional e internacional. Esto, junto a otros factores, ha hecho que algunos autores postularan la transnacionalización de facto de la política migratoria en los países centrales (Sassen, 2003) o la discutieran en ámbitos regionales periféricos como América Latina (Stuhldreher, 2006).

2 Este artículo ${ }^{3}$, primero, describe en términos generales la emergencia de una nueva agenda política internacional sobre migraciones y su desarrollo en el ámbito de la región sudamericana, mostrando algunos de los cambios que se estarían produciendo a partir de la intervención de actores políticos que desarrollan actividades internacionales, multinacionales y transnacionales ${ }^{4}$. Segundo, se analiza el caso argentino, a través de documentos oficiales e intervenciones públicas de funcionarios de gobierno involucrados o próximos al ámbito de las migraciones, indagando particularmente las recientes transformaciones políticas en materia migratoria ${ }^{5}$. Se muestra que la Argentina, bajo una realidad migratoria muy distinta a la de otros países receptores de inmigración y a la de las sociedades capitalistas avanzadas, constituye un caso que evidencia, o al menos permite discutir, el desplazamiento parcial del concepto de nacionalidad desde un principio que refuerza la soberanía y la autodeterminación del Estado a otro que lo define como responsable ante todos sus residentes bajo el estatuto de los derechos humanos (Sassen, 2001; 2003), acompañado de la ampliación de 
la noción de ciudadanía, y del deslizamiento de la noción de asimilación a la de pluralismo cultural en la formulación de las políticas públicas ${ }^{6}$.

\section{La internacionalización de la política migra to ria y la emergencia de una nueva agenda política}

3 Es creciente el número y la diversidad de actores sociales que se ocupa del fenómeno migratorio en la actualidad: desde organismos internacionales y comunidades transnacionales de migrantes hasta instituciones gubernamentales, no gubernamentales y académicas buscan promover determinadas visiones y prácticas alrededor del tema. Las miradas realistas o románticas sobre las migraciones no son propiedad exclusiva de ningún actor social en particular y sería reduccionista atribuir ciertos discursos o acciones a determinados actores por el hecho de que actúen principalmente a nivel global o local, sean gubernamentales o no, etc. Esto implicaría desconocer la importancia que tienen las relaciones y redes transnacionales (Mato, 2004), las cuales se cristalizan en espacios disímiles, durante el proceso de construcción de las agendas internacional, regional y nacional.

\section{Política migratoria: del control de los ingresos a la gestión de las migraciones}

En la actualidad, paralelamente o frente a una visión de la política migratoria fundamentada en el control y la seguridad nacional que comete la falacia de asociar la inmigración al terrorismo, cuya expresión más acabada la constituye la política migratoria estadounidense ${ }^{7}$, diversas agencias internacionales y organismos gubernamentales proponen o adhieren a una perspectiva emergente sobre el fenómeno migratorio que se apoya en la noción de gestión de las migraciones, perspectiva que también ha penetrado en algunas organizaciones no gubernamentales y otros actores de la sociedad civil. Desde este enfoque, apoyado en buena medida en la lógica costobeneficio -encarnada en la figura del "balance contable" (Sayad, 1998)- y bajo una visión tanto realista como pragmática, que reconoce la imposibilidad de controlar eficazmente (en el sentido de "restricción") los flujos migratorios, especialmente aquellos de carácter "irregular", los migrantes son clasificados en base a una supuesta (in)utilidad, estableciendo una serie de "ventajas" y "desventajas" (no sólo económicas) de la inmigración. La novedad es que ahora las migraciones son consideradas mayormente en términos de "ventajas" -se desplaza aquí la noción de "problema" asociado a las migraciones durante décadas en la agenda mundial-, acentuando las oportunidades que ofrecen y atribuyéndoles una capacidad de transformación inaudita: el papel de los migrantes en el crecimiento económico, el desarrollo y la reducción de la pobreza. Bien sabemos que una cuestión es afirmar que la migración internacional contribuye a la economía global y que su expansión depende de la movilidad de mano de obra y otra muy diferente es sostener que el aporte de los migrantes al crecimiento de la economía mundial representa un progreso para el bienestar general, incluidos los sectores y clases sociales que se encuentran bajo condiciones de explotación y exclusión social, entre ellos los "trabajadores migrantes". Consecuentemente, desde este enfoque también se distingue entre los flujos migratorios "deseables" y "no deseables" para "el desarrollo" en función de su carácter ordenado/desordenado, voluntario/forzoso y 
reducido/masivo, siendo apreciadas positivamente las migraciones internacionales mientras no alteren o favorezcan la reproducción del capitalismo global.

Dentro de las prioridades de esta agenda política, las temáticas de principal interés se relacionan con los derechos humanos de los migrantes, la migración laboral e irregular y los desplazamientos forzosos, el tráfico y trata de personas, la seguridad nacional e internacional y la gobernabilidad de las migraciones. No se trata necesariamente de una visión integral ni unívoca. Su desarrollo difiere según los intereses de los actores sociales involucrados y las especificidades del contexto sociohistórico: en algunas versiones aparece acentuada, por ejemplo, la regulación de la migración laboral y la migración llamada "irregular" o la defensa de los derechos humanos, mientras que en otras se enfatiza la seguridad nacional, suprimiendo cláusulas relativas a los derechos de los migrantes. La diferencia entre aquellos modelos inspirados en los derechos humanos, por un lado, y en la seguridad nacional o internacional, por el otro, radica en que en el primero la seguridad y el control aparecen como uno de sus componentes mientras que en el segundo encuentra en ellos su fundamento.

6 Cabe destacar que algunos de los tópicos de interés registrados en la agenda internacional como migración y seguridad se apartan considerablemente de las reivindicaciones de los movimientos sociales y las organizaciones de la sociedad civil altermundialista, mientras que otros como la defensa de los derechos humanos de los migrantes muestran, al menos en apariencia, cierta coincidencia. Estas intersecciones se vinculan, en algunos casos, con la búsqueda de consenso y el abandono (parcial) del criterio de unilateralidad por parte de los organismos internacionales. También habría que añadir que estos cruces pueden resultar coincidentes sólo en apariencia. Esto lo ilustra bien el tema de los derechos humanos de los migrantes: los derechos humanos pueden ser utilizados tanto como un instrumento hegemónico como contrahegemónico (Santos, 2002). Es decir, más allá de las aparentes o relativas coincidencias entre la agenda dominante y alternativa, se pueden distinguir en principio dos formulaciones opuestas: una que responde a un modelo de equilibrio orientado al gerenciamiento de las migraciones y otra que aspira a constituirse en una respuesta política, basada en una perspectiva del conflicto, a la dominación y la desigualdad entre los países centrales y periféricos. El primer modelo aceptaría como dado lo que cuestiona el segundo: el orden social, económico, político y cultural dominante.

\section{Migraciones y política: la agenda sudamericana}

7 También en el escenario latinoamericano, según algunos autores, la consolidación del nuevo orden mundial estaría determinando un cambio en las lógicas con que tradicionalmente se han definido las políticas migratorias. En la década de los noventa, la región sudamericana experimenta cambios específicos en el tratamiento que reciben las migraciones internacionales, donde la idea de corresponsabilidad y la búsqueda de consenso entre países de origen y de llegada se convierten en las principales directrices de las políticas migratorias, lo cual se constata en el incremento de las acciones bi y multilaterales (de antigua data en la región) frente a la unilateralidad que han asumido tradicionalmente las políticas migratorias (Mármora, 2003). Estos cambios se han desarrollado en el marco de procesos de integración subregionales, como la Comunidad Andina de Naciones (CAN) y el Mercado Común del Sur (Mercosur), y de foros consultivos regionales como la Conferencia Regional de Migraciones (más conocida 
como "Proceso Puebla"), cuya primera reunión tuvo lugar en 1996, y la Conferencia Sudamericana de Migraciones" (denominada también "Foro Sudamericano sobre Migraciones"),iniciada en el año 2000, después que se acordara su inicio en el Encuentro Sudamericano de Migraciones, Integración y Desarrollo de 1999 realizado en Lima $^{10}$. Este espacio político multilateral, cuya formación responde en parte a los compromisos asumidos por los gobiernos en la Conferencia Mundial de Población de El Cairo (1994), es considerado también como un intento de consolidación, ampliación y programación sistemática de los desarrollos alcanzados en los procesos de integración subregional en América del Sur, tanto en la CAN como en el Mercosur (Mármora, 2003: 133).

Es necesario precisar que estos acuerdos económico-comerciales y procesos consultivos, básicamente de carácter intergubernamental, han contado con la intervención de organismos internacionales y diferentes organizaciones de la sociedad civil, cuya diversidad y peso es mayor en los procesos consultivos regionales que en los espacios de integración subregional. La participación de organizaciones de la sociedad civil en estos foros consultivos regionales no se reduce a una invitación formal: por un lado, los Estados reconocen ahora que la complejidad y multidimensionalidad del fenómeno migratorio hace necesaria la participación de distintos interlocutores, y por el otro, diversos movimientos sociales y organizaciones no gubernamentales involucrados en el tema han obtenido mayor visibilidad política y capacidad de negociación, intensificando y extendiendo sus actividades mediante el establecimiento de redes nacionales y regionales ${ }^{11}$.

Por otra parte, los temas tratados en los acuerdos intergubernamentales permiten conocer las prioridades de la agenda política de los Estados sudamericanos en materia de migraciones, las cuales difieren según el espacio de negociación. Dentro de los procesos de integración subregional en América del Sur, la CAN y el Mercosur, en correspondencia con el carácter básicamente económico de estos bloques, las migraciones internacionales son tratadas en el marco de los asuntos sociolaborales, recibiendo especial atención lo relativo a la "libre movilidad de la mano de obra" o las “migraciones laborales"12. En el proceso de consulta regional dedicado específicamente a las migraciones, la CSM, la cuestión migratoria es tratada atendiendo aspectos que atañen separada o simultáneamente los intereses de los migrantes y de los propios Estados, lo cual se refleja por ejemplo en el plan de acción adoptado. Entre las prioridades se registra la promoción de los derechos humanos de los migrantes y sus familias, la vinculación entre los nacionales en el exterior y sus países de origen, la inserción de los migrantes en los países de destino, la regularización migratoria, la gobernabilidad de los flujos migratorios, la generación de información y conocimiento acerca de los procesos migratorios intraregionales y extraregionales, la modernización de las administraciones nacionales migratorias y la actualización de las legislaciones migratorias nacionales. En términos más generales, como se desprende de la última reunión de la CSM realizada en Asunción en el mes de mayo de 2006, los grandes ejes temáticos alrededor de los cuales se reafirman los objetivos son: derechos humanos de los migrantes, migración y desarrollo y gobernabilidad migratoria. El hecho de que estas áreas temáticas guarden una estrecha relación con los lineamientos surgidos en eventos organizados por organismos internacionales como las Naciones Unidas y la OIM pone en cuestión la autonomía de los Estados a la hora de definir la agenda política regional ${ }^{13}$. 
10 El caso argentino, como veremos a continuación, da cuenta de algunos de los cambios en materia de política migratoria que se están desarrollando en el escenario mundial y latinoamericano, particularmente en la región sudamericana, interviniendo activamente en la conformación de la emergente agenda política. A escala regional, como miembro del Mercosur, la Argentina ha establecido convenios bi y multilaterales con distintos países de la región. Entre otras acciones se destaca la firma de convenios migratorios con Bolivia y Perú en el año 1998, completados a través de protocolos adicionales, y del Acuerdo sobre Residencia para Nacionales de los Estados Partes del Mercosur, Bolivia y Chile en el 2002, cuyo proyecto fue aprobado en la Reunión de Ministros del Interior (creada en 1996), siendo incorporado posteriormente a la actual legislación migratoria. También participa desde sus comienzos de la Conferencia Sudamericana sobre Migraciones (fue sede de la reunión realizada en el año 2000) y de la Conferencia Regional de Migraciones en calidad de observador. En el ámbito nacional, la aprobación de la nueva ley de migraciones (sancionada en diciembre de 2003 y promulgada de hecho en enero de 2004), la ley 25 871, resulta un vuelco decisivo en materia de políticas migratorias al derogar la Ley General de Migraciones y Fomento de la Inmigración de 1981, más conocida como Ley Videla, basada en la doctrina de seguridad nacional. En su elaboración, aparte de los organismos del Estado, intervinieron (con desigual peso político), nucleados fundamentalmente alrededor de una red de instituciones denominada Mesa de organizaciones en defensa de los derechos de los inmigrantes ${ }^{14}$, organizaciones de derechos humanos, instituciones de la Iglesia Católica, representantes de colectividades de inmigrantes, sindicatos y especialistas en migraciones ${ }^{15}$. La inclusión de diversos actores de la sociedad civil en este proceso forma parte de las nuevas formas de legitimación que estaría adoptando la instrumentación de las políticas públicas en la actualidad. Por otro lado, la cuestión migratoria en general y la construcción de esta ley en particular puso también de manifiesto las disputas, divergencias y contradicciones existentes en el seno del Estado $^{16}$.

\section{De la retórica de la exclusión a la retórica de la inclusión}

11 En la Argentina, las migraciones internacionales han formado una parte constitutiva de los proyectos políticos del Estado. A diferencia de otros países de la región, "el aparato estatal argentino posee una temprana y extensa experiencia en la formulación de políticas migratorias" (Novick, 1997: 86). A lo largo de más de un siglo de inmigración en el país, el discurso oficial del Estado argentino ha oscilado entre una visión que contempla la inmigración como "contribución" o "aporte" y otra que la concibe en términos de "problema" o "amenaza", lo cual configura, en cierta forma, un sistema de clasificación que distingue entre potenciales "admitidos" o "rechazados", ya sea para ingresar y permanecer en el territorio o para formar parte de la nación ${ }^{17}$. Esto no significa que la relación entre locales/inmigrantes o nacionales/ extranjeros se reduzca simplemente a una relación aceptación $/$ rechazo $^{18}$. Pero más allá de la política permisiva o restrictiva desarrollada en el país, distintas fórmulas de exclusión han tenido lugar a lo largo de toda la historia migratoria argentina y al Estado como uno de sus principales promotores. Hubo siempre una notable preferencia por las corrientes migratorias europeas (a su vez, algunas de ellas en particular) frente a las latinoamericanas y los 
criterios de clasificación se basaron no sólo en el origen de los flujos migratorios, sino también en su composición: los enfermos, los viejos, los discapacitados y los anarquistas engrosaron también la lista de los inmigrantes "indeseables".

En las últimas décadas del siglo XX hubo una actualización de los discursos y políticas de exclusión, resurgiendo con intensidad la figura de la inmigración como "problema" o "amenaza". Durante los años noventa, la inmigración latinoamericana -no sólo ellasirvió de pretexto para explicar distintas situaciones sociales por las que atravesaba el país y legitimar una serie de medidas económicas enmarcadas en las políticas de ajuste estructural del programa neoliberal que se pretendía consolidar ${ }^{19}$. Fue desde determinados ámbitos del Estado, especialmente aquellos más próximos a la problemática migratoria, que se asociaron los problemas sociales y económicos a la inmigración, encontrando en los inmigrantes limítrofes los responsables de aquellos efectos provenientes de las reformas económicas implementadas en la Argentina bajo el paradigma neoliberal. Como se ha señalado en reiteradas ocasiones, los inmigrantes de países vecinos -especialmente bolivianos, paraguayos y peruanos- fueron interpelados básicamente como una amenaza al trabajo, la sanidad y la seguridad: en sus declaraciones, reproducidas por los medios de comunicación más poderosos, altos funcionarios públicos adjudicaban el desempleo, el cólera y la inseguridad a los inmigrantes latinoamericanos mientras las causas estructurales de la crisis económica y social fueron desestimadas en gran parte del debate público hasta que finalmente se hiciera evidente. Esta retórica de la exclusión se plasmó en políticas restrictivas y en prácticas de carácter persecutorio y represivo dirigidas a la inmigración limítrofe fundadas en la Ley General de Migraciones y de Fomento de la Inmigración (Ley 22439) de 1981 instaurada por la última dictadura militar (1976-1983) y mantenida vigente hasta el año 2003 durante los sucesivos gobiernos democráticos ${ }^{20}$.

13 A inicios de la presente década, después que se desatara la crisis social y política de diciembre de 2001, se advierte un giro significativo en la retórica del Estado respecto a la inmigración. En la actualidad aparecen indicios de una reconfiguración de los discursos y políticas del Estado frente a las migraciones internacionales y la diversidad cultural inaugurando una retórica de la inclusión, basada en la perspectiva de los derechos humanos, la ciudadanía comunitaria y el pluralismo cultural, frente a la retórica de la exclusión predominante en la década de los noventa. A diferencia de las décadas anteriores, el discurso oficial del Estado actual no se apoya, al menos abiertamente, en la figura de la inmigración limítrofe como "problema" o "amenaza" Por el contrario, ahora se destaca el aporte o la contribución que han hecho y hacen los inmigrantes, principalmente en el campo de la economía y la cultura, reconociendo la inmigración como una "necesidad".

[...] El tiempo fue pasando, las migraciones europeas descendieron, las limitrofes se mantenían de manera constante, vientos raros comenzaron a correr por la Argentina y se llegó a sostener que no necesitábamos migrantes, y no sólo que no los necesitábamos, sino que muchas veces eran los causales de problemas como la desocupación y la inseguridad. (Funcionario de gobierno de la provincia de Santa Fe en el Seminario Migraciones y Derechos Humanos, Rosario, 2005)

[...] Argentina le debe mucho a las migraciones, a las migraciones europeas, a las limitrofes, a las asiáticas, a las latinoamericanas, cada una con su idiosincrasia y cada una con su aporte. (Funcionario de la DNM en el Seminario Migraciones y Derechos Humanos, Rosario, 2005)

[...] La migración, la convivencia de nacionalidades diversas, la diversidad cultural enriquece la constitución de la propia identidad, tanto personal como nacional, no resta, no es una 
amenaza, por el contrario suma, aporta en materia cultural, aporta en fuerza de trabajo, aporta en intercambio social y educativo, nutre a nuestro conocimiento, contribuye a una mayor amplitud mental, sus efectos son sumamente positivos. De hecho así se constituyó nuestra propia identidad e historia nacional a lo largo de los años. (Legislador nacional en el Seminario Migraciones y Ciudadanía, Rosario, 2006) los cambios en la política migratoria se originarían a partir de la constatación de algunos elementos de la realidad migratoria argentina. El diagnóstico incluye la ubicación geográfica del país en el Cono Sur y su extensa frontera política, la Argentina como país de inmigración y -más recientemente- de emigración y el fracaso o relativo éxito de normas y medidas políticas y administrativas.

[...] Hablamos de realidades de una Argentina geográficamente inserta en América del Sur, donde tenemos una enorme frontera con muchísimos pasos habilitados y muchos otros sin habilitar, pero que permiten el ingreso fácil de ciudadanos de países limitrofes a nuestro territorio. Hablamos de una realidad histórica que nos signa como un país de recepción, y una realidad más reciente que nos signa como un país de emigración, de los argentinos buscando un mejor destino afuera. (Funcionario de la Dirección Nacional de Migraciones en el Seminario Migraciones y Derechos Humanos, Rosario, 2005)

Es muy significativo el giro que se produce entre el discurso oficial actual y el de las décadas pasadas. Visto en perspectiva histórica, la ruptura más evidente lo constituye la introducción de la perspectiva de los derechos humanos y el consecuente abandono de la doctrina de la seguridad nacional adoptada en la normativa migratoria anterior, un logro político destacable ${ }^{22}$. La incorporación de la noción de "ciudadanía comunitaria", por su parte, constituye otro de los quiebres con la tradición del pensamiento migratorio argentino. Precisamente, la aprobación de la nueva ley de migraciones (Ley 25871) se fundamenta "en la necesidad de poner fin a la vigencia de la Ley Videla y, a la vez, definir las bases fundamentales para una política migratoria y poblacional para la República Argentina de cara al nuevo siglo y a las nuevas realidades del contexto regional e internacional" (Giustiniani, 2004: 19). Sin embargo, la adopción del pluralismo cultural, otro de los pilares de la retórica de la inclusión en el ámbito de las migraciones, muestra continuidades significativas con la manera en que tradicionalmente se ha entendido y practicado en la Argentina la incorporación de los migrantes a la sociedad de destino/recepción: la penetración del discurso pluralista en distintos organismos estatales no ha supuesto el abandono de las ideas asimilacionistas. Asimismo, mientras los discursos y políticas del Estado se basan en la articulación de los derechos humanos, la ciudadanía comunitaria y el pluralismo cultural -presentados por separado sólo con fines analíticos-, las prácticas estatales están dirigidas fundamentalmente a la regularización de la situación administrativa de los migrantes (uno de los principios del enfoque de la "gobernabilidad de las migraciones") constituyéndose en el eje transversal de las acciones emprendidas recientemente.

\section{La migración como derecho humano y los migrantes como sujetos de derechos ${ }^{23}$}

16 A diferencia de otras realidades nacionales, en la Argentina la defensa de los derechos de los migrantes no surge únicamente como respuesta a la coyuntura internacional. También se inscribe en la propia experiencia política del país. Como señala Jelin, en la transición política posterior a la dictadura militar, si bien la cuestión migratoria no ocupaba el centro de la agenda estatal, "el marco interpretativo dominante ponía el énfasis 
en defender los 'derechos humanos' que habían sido violados durante la dictadura y en ampliar la noción de derechos humanos para convertirla en la piedra fundacional del nuevo orden constitucional", lo cual posibilitó -junto a la apertura de mecanismos de expresión directa de demandas ciudadanas- que el tema migratorio ingresara en los ámbitos del Estado (Jelin, 2006: 59).

17 Tuvieron que transcurrir muchos años para que en el marco del Estado se adoptaran medidas y decisiones políticas nacionales tendientes a definir una posición favorable a los derechos humanos en materia de migraciones. La Ley Videla (Ley 22439) se mantuvo vigente en el país a lo largo de más de dos décadas hasta su derogación en el año 2003. Como se señala en un informe del Centro de Estudios Legales y Sociales (CELS), esta normativa era violatoria de diversas normas de la Constitución Nacional y de los tratados de derechos humanos que se incorporaron con la reforma constitucional de 1994; se inspiraba en una concepción represiva que desconocía los derechos de las personas migrantes, desconociendo dos principios fundantes del sistema jurídico argentino: el derecho a la igualdad y a la no discriminación. Esta ley le otorgaba facultades excesivas a la DNM dependiente de la Secretaría de Población del Ministerio del Interior. Estaba autorizada a "controlar el ingreso, egreso y permanencia y ejercer el poder de policía de extranjeros en todo el territorio de la República" (artículo 40). Como se dispone en su articulado, este organismo del Poder Ejecutivo estaba facultado a allanar aquellos lugares donde se sospechara la presencia de inmigrantes irregulares, detenerlos sin orden judicial y expulsarlos. Entre otras violaciones a los derechos humanos contenidas en esta ley, se destaca la obligación legal de denunciar la existencia de una persona extranjera sin permiso de residencia ante la autoridad migratoria, las restricciones o prohibiciones respecto a la educación, al trabajo y a la libre circulación en el territorio nacional y la ausencia de garantías procesales (inexistencia de debido proceso y recurso judicial efectivo, allanamiento y detención sin orden judicial) (CELS, 1999).

18 En materia de políticas públicas, esta normativa sirvió para legitimar numerosas prácticas de exclusión social. Consecuente con una visión sobre la inmigración asociada a la "amenaza", el Estado impedía o restringía, por ejemplo, el acceso a la educación y violaba el derecho a ella, especialmente de aquellos inmigrantes o hijos de inmigrantes en condiciones de "irregularidad migratoria". Organismos de derechos humanos como el CELS han denunciado los obstáculos que tuvieron (y tienen) los inmigrantes o hijos de inmigrantes que carecen de la documentación requerida para el acceso, promoción y acreditación de la escuela primaria. En uno de sus documentos se destaca que "(l)os funcionarios de la Dirección de Enseñanza Media de la provincia de Córdoba restringen el ingreso de los chicos extranjeros que no acreditan certificados de residencia de la DNM, tal como lo exige, según señalan, la ley de migraciones" (CELS, 1999). En el caso de la educación media la ley 22439 establecía que "los institutos de enseñanza media o superior, ya sean públicos o privados, nacionales, provinciales o municipales, solamente podrán admitir como alumnos a aquellos extranjeros que acrediten, para cada curso lectivo su calidad de 'residentes permanentes' o 'residentes temporarios', debidamente habilitados a tales efectos" (artículo 102) ${ }^{24}$.

19 La Ley Videla tuvo su reflejo más claro en la presidencia de Carlos Menem, durante el quinquenio 1995-1999, alcanzando la mayor política restrictiva desde el regreso de la democracia (Mármora, 2004: 61). Aunque no prosperó el establecimiento de una ley migratoria más estricta, se consiguieron mayores detenciones y expulsiones de 
inmigrantes de los países vecinos. El crecimiento de la llamada migración ilegal o irregular fue uno de los resultados de la implementación de estas medidas restrictivas y represivas, actuando el Estado como productor de "ilegalidad". En lugar de facilitar la radicación en el país, el Estado estableció requisitos y exigencias desajustadas a la realidad de buena parte de los inmigrantes, instaurando aún mayores límites en el acceso a los derechos ciudadanos.

Con la aprobación de la nueva ley de migraciones (2003) la migración es reconocida como un derecho humano y los migrantes como sujetos de derecho. El derecho a la migración es considerado "esencial e inalienable de la persona y la República Argentina lo garantiza sobre la base de los principios de igualdad y universalidad" (artículo 4). Además, ahora el Estado deberá asegurar "las condiciones que garanticen una efectiva igualdad de trato a fin de que los extranjeros puedan gozar de sus derechos y cumplir con sus obligaciones" (artículo 5) y "el acceso igualitario a los inmigrantes y sus familias en las mismas condiciones de protección, amparo y derechos de los que gozan los nacionales" (artículo 6). Por tanto, el Estado se compromete a velar por los derechos económicos, sociales, culturales y políticos de los migrantes reconocidos en la normativa nacional e internacional. También establece una serie de medidas que facilitan la admisión, el ingreso y la permanencia de los migrantes así como su acceso a servicios sociales básicos como salud, educación, justicia, trabajo, empleo y seguridad social, independientemente de la condición de "regularidad migratoria" en algunos casos. Por ejemplo, en el campo de la educación, al contrario de lo que se proponía con la Ley Videla, la nueva normativa migratoria establece que la irregularidad migratoria no impedirá en ningún caso la admisión a un establecimiento educativo, ya sea de carácter público o privado; nacional, provincial o municipal; primario, secundario, terciario o universitario (artículo 7). Además, las autoridades de las escuelas ya no deberán denunciar a aquellos que se encuentren en dicha situación (como lo exigía la Ley Videla), sino que "deberán brindar orientación y asesoramiento respecto de los trámites correspondientes a los efectos de subsanar la irregularidad migratoria" (artículo 7). En suma, en términos de Novick, el modelo de sociedad que subyace a esta ley remite a "una sociedad multicultural, integrada en la región e inclusiva, que respeta los derechos de los extranjeros y valora su aporte cultural y social" (Novick, 1994: 84).

Ahora bien, desde los organismos del Estado se promueve el enfoque de los derechos humanos de los migrantes sosteniendo una mirada que no abandona la lógica de costo/ beneficio de la inmigración, lo cual expresa, según nuestro punto de vista, una de las tensiones o contradicciones que genera la búsqueda de compatibilidad entre la legislación internacional sobre derechos humanos y los intereses del Estado. Como vimos anteriormente, el discurso oficial actual, en principio, está dirigido a destacar los "beneficios" o "ventajas" de la inmigración antes que sus "costos" o "desventajas", distanciándose del discurso dominante de los noventa que le atribuía la responsabilidad de parte de los problemas sociales y económicos del país. Pero enfocada la migración como problema o como contribución, si bien pueden tener consecuencias muy distintas, comparten la visión en que se apoyan: la migración es evaluada en función de una lógica de costo/beneficio. Así, la imagen del inmigrante queda signada por una visión dualista que lo concibe en términos negativos o positivos, ya sea atribuyéndole la responsabilidad de los problemas sociales o económicos del país, ya sea rescatando su contribución al crecimiento económico o su aporte al enriquecimiento cultural. Esta visión promueve la idea de que la presencia es legítima en tanto sea una contribución o ilegítima en tanto sea un problema. Además, la presencia legítima o no del inmigrante, 
se establece de acuerdo a la manera en que participa de la construcción de la "patria chica" (Argentina) más que de la "patria grande" (Latinoamérica). Bajo una visión de la migración como derecho humano, en cambio, no debería ser relevante si ella contribuye al crecimiento económico o aporta a la riqueza cultural del país, si causa mayores desventajas que beneficios ${ }^{25}$.

Otro de los aspectos a tener en cuenta es la relación entre los derechos humanos y la condición de regularidad o irregularidad migratoria. Hasta la aprobación de la nueva ley de migraciones, el acceso a ciertos derechos estuvo vedado para los "inmigrantes irregulares", contrariando la normativa internacional sobre derechos humanos que se incorpora con la reforma de la Constitución Nacional de 1994. Con la nueva legislación migratoria, como veíamos más arriba, se reconoce el derecho a la educación (artículo 7) y a la salud (artículo 8), "cualquiera sea su situación migratoria". Asimismo, el empleador deberá cumplir "con las obligaciones emergentes de la legislación laboral respecto del extranjero, cualquiera sea su condición migratoria" a la vez que "en ningún modo se afectarán los derechos adquiridos por los extranjeros, como consecuencia de los trabajos ya realizados, cualquiera sea su condición migratoria" (artículo 56). En cuanto a los procesos de detención y expulsión de los migrantes, la nueva ley de migraciones también establece una serie de derechos y garantías para aquellos inmigrantes cuya permanencia en el país se constate como "irregular" ${ }^{26}$. Sin embargo, convertida la regularización de la situación migratoria en el eje de las acciones estatales en materia migratoria, el mensaje de la campaña de difusión del Programa Nacional de Normalización Documentaria Migratoria sugiere que el goce de todos los derechos está supeditado a la regularidad o irregularidad de la condición administrativa del migrante: primero pregunta si “¿Usted es inmigrante?”, luego afirma que "Usted tiene derechos" y finalmente indica que "Para hacerlos valer, regularice su situación".

23 Finalmente, si bien el núcleo duro del discurso oficial está centrado en los derechos humanos de los migrantes, la justificación del plan de regularización migratoria se basa no sólo en las necesidades de los inmigrantes, sino también en los intereses económicos del Estado. En ocasiones, cuando se argumenta a favor de la "regularización migratoria" se brindan los mismos motivos que se sostuvieron durante la década de los noventa, circunscriptos a la lógica costo/beneficio. Es decir, además de apoyarse en esta lógica, contradiciendo en buena medida el discurso oficial actual, se utilizan argumentos que privilegian los "costos" antes que los "beneficios" de la inmigración. En el sitio web del Programa Nacional de Normalización Documentaria Migratoria, más conocido como "Patria Grande", se sostiene que "un indocumentado provoca inevitablemente una baja salarial", a la vez que "sus actividades no generan tributo alguno a la sociedad, sólo genera riqueza para la economía informal"; que "un trabajador regularizado aporta a la economía nacional, a través de los descuentos de sus remuneraciones, sumas mucho mas importantes"; que "un indocumentado sólo puede recurrir a la salud pública recargando los costos de la misma cuando, a través de su regularización, podría aliviar los costos estaduales utilizando otras estructuras de atención de la salud, obras sociales, salud privada etc." ${ }^{27}$

\section{Migraciones e integración regional: la ciudadanía comunitaria} construcción de la Argentina como nación (desconociendo otros hechos y actores 
sociales relevantes como la pretensión de exterminar los pueblos indígenas) y se afirma el regreso a una política de "puertas abiertas" en consonancia con la "mejor tradición argentina", aquella que establece la Constitución Nacional de 1853 cuando se dirige a "todos los hombres del mundo que quieran habitar el suelo argentino", buscando restaurar la imagen de una Argentina abierta, tolerante y plural para conformar, en un contexto de integración regional, la "patria grande". Este pretendido regreso a la política de puertas abiertas se apoya, por un lado, en una visión idílica de lo que fue la recepción de la inmigración de ultramar de fines del siglo XIX y comienzos del XX, no reconociendo, al menos explícitamente, que la política de puertas abiertas también implicó conflictos y contradicciones, además de procesos y mecanismos de inclusión/ exclusión, ya sea de acuerdo al origen o a la composición de los flujos migratorios. Por el otro, si bien se reconoce que esta política de puertas abiertas tiene lugar en el marco de un proceso de integración regional, ya sea acotado o amplio, no admite explícitamente que se desarrolla bajo una realidad migratoria (intraregional) muy distinta a la de otros países tradicionales o recientes de inmigración y bajo un contexto histórico muy diferente al de principios del siglo XX, lo cual permite relativizar la postura de "avanzada" o "contraria a la tendencia internacional" que estaría asumiendo según el discurso oficial la política migratoria actual ${ }^{28}$.

[...] Argentina está desarrollando una política migratoria amplia, de puertas abiertas, y es importante tener en cuenta la incidencia que la realidad del Mercosur ha tenido en la adopción de esta política. (Funcionario de la Dirección Nacional de Migraciones en el Seminario Migraciones y Derechos Humanos, Rosario, 2005)

[...] Por eso, igualdad de responsabilidades, igualdad de derechos, igualdad de posibilidades y una patria grande que nos contenga en una etapa inicial a todos los que integramos el Mercosur y los países del América del Sur, y por supuesto, al resto de los países del mundo. (Mensaje presidencial en la inauguración del Programa Nacional de Normalización Documentaria Migratoria)

La política migratoria actual busca extender la noción de ciudadanía, acotada generalmente a los nacionales de una única unidad estatal, a los Estados Parte y Asociados del Mercosur. Esta idea de "ciudadanía comunitaria" se refleja en la expresión de "Patria Grande" que utiliza el Estado, con claras reminiscencias a la "unión latinoamericana", para encuadrar una de las principales acciones que desarrolla la DNM: el Programa Nacional de Normalización Documentaria Migratoria. De esta manera, el Estado, nuevamente, encara uno de los pilares de sus discursos y políticas a través de la regularización migratoria, convirtiéndose en el eje transversal de sus prácticas. El relato oficial de la gestión actual sostiene que mientras este tipo de medidas fueron implementadas anteriormente como una respuesta coyuntural, obteniendo escasos resultados, ahora se pretende jerarquizarla otorgándole a la regularización migratoria rango de "política de Estado".

Durante la década de los noventa los intentos de regularización migratoria se materializaron en amnistías y convenios migratorios bilaterales con Estados vecinos. Tanto con la amnistía de 1992 destinada a migrantes limítrofes como con los convenios migratorios firmados con Bolivia y Perú en 1998 (Leyes 25.098 y 25.099), completados a través de protocolos adicionales, el Estado argentino, motivado también por razones económicas como controlar la evasión y pérdida fiscales, se proponía obtener la regularización de aquellos migrantes que se encontraban en una "condición migratoria irregular" 29 . Desde la perspectiva de la gestión actual de la DNM, estas amnistías y convenios no dejaron de ser soluciones coyunturales y no tuvieron los resultados buscados. En cambio, el Acuerdo de Residencia de Estados Partes del Mercosur, establecido 
en la Reunión de Ministros del Interior e incorporado como criterio a la nueva ley de migraciones, no sólo constituye la "base" del actual programa de regularización, sino que también es visto, en palabras de un funcionario de la DNM, como "la solución a la problemática de la irregularidad". Según el Acuerdo, los nacionales de un Estado Parte podrán ahora residir en el territorio de otro Estado Parte mediante la acreditación de su nacionalidad y el cumplimiento de determinados requisitos (entre los cuales se destaca la carencia de antecedentes judiciales y/o penales y/o policiales).

Pero esta ampliación de la ciudadanía a un territorio más abarcativo (la región sudamericana) se restringe en relación al ejercicio de los derechos políticos, un elemento constitutivo de aquél concepto. El derecho al voto, por ejemplo, sólo pueden ejercerlo aquellos extranjeros que cuenten con una residencia permanente de determinada antigüedad, limitado a la vez a las elecciones municipales. Las elecciones de alcance provincial y nacional quedan reservadas para los "nacionales". Además, la nueva normativa -como advierte Ceriani- podría vulnerar los derechos de los migrantes que pudieran provenir de otros países o regiones en el caso que se llegaran a establecer "ciudadanos de distinta categoría y derechos según su nacionalidad", generando políticas de carácter discriminatorio y excluyente, además de legitimar prácticas de explotación y marginación social, económica y cultural como ocurre en la Unión Europea (Ceriani, 2004: 126).

Por otra parte, el hecho de que la "regularización migratoria" sea el eje de las prácticas estatales en materia migratoria, hace que la compleja "problemática migratoria" sea simplificada en términos de una "problemática de (ir)regularidad migratoria". En el terreno de la ciudadanía, esto no significa que dejemos de reconocer la importancia que tiene la regularización de la situación administrativa de los migrantes mal llamados "indocumentados" para disfrutar de determinados derechos. Lo que no habría que olvidar es que, como señala Jelin, "aunque la legalidad legitima la participación o el acceso a ciertos derechos, no los asegura". De ahí la necesidad de ocuparse no sólo del plano legal, sino también del acceso real a los derechos y deberes ciudadanos y a la participación como miembros de la nación, lo cual supone una noción de ciudadanía entendida como un proceso dinámico de luchas por la ampliación y el ejercicio real de los derechos ciudadanos que trasciende los aspectos formales (Jelin, 2006: 54).

Finalmente, desde el discurso oficial se destaca que el Acuerdo de Residencia haya resultado de la Reunión de Ministros del Interior, dado que es en este ámbito de gobierno donde se define la política de seguridad a escala nacional y regional. Se afirma que la política de "puertas abiertas", sostenida por este Acuerdo, se estaría desarrollando a pesar de la tendencia internacional de cierre de las fronteras por motivos de seguridad, especialmente fortalecida desde los acontecimientos del 11 de septiembre, y la asociación entre migración y terrorismo.

[...] No es un dato menor que este acuerdo se haya suscripto en el ámbito de la reunión de Ministros de Interior del Mercosur si tenemos presente que es precisamente bajo estos ministerios que se desarrolla toda la estrategia de seguridad de nuestros países y de la región. Cuando en otras regiones del mundo se cierran las puertas a los migrantes, basándose en temas de seguridad y de oscurantismo frente al terrorismo, en el Mercosur las puertas se abren. (Funcionario de la Dirección Nacional de Migraciones en el Seminario Migraciones y Derechos Humanos, Rosario, 2005)

[...] Volver a la política migratoria de puertas abiertas en la República Argentina no es fácil desde el espacio de gestión porque estamos contradiciendo tendencias internacionales que ligan a la migración con el terrorismo. (Funcionario de la Dirección Nacional de Migraciones en el Seminario Migraciones y Derechos Humanos, Rosario, 2005) 
Ahora bien, como señalábamos anteriormente, aunque según el discurso oficial esta política de "puertas abiertas" gravitaría sobre la noción de los derechos humanos, a nuestro juicio su fundamento real lo encuentra en la política actual de integración regional que, por otra parte, no desconoce el tema de la seguridad. Precisamente, uno de los fundamentos del programa de regularización se erige sobre aspectos relativos al control de las fronteras y del territorio. Según un funcionario de la DNM, "documentarlos [a los migrantes] y saber quién está en el territorio pareciera ser lo más lógico desde el punto de vista de la seguridad". Y agrega que "la realidad nos dice que es mucho mejor saber quién reside en nuestro territorio, y tenerlo documentado, tenerlo regularizado para poder hacer un seguimiento de los mismos". No sólo se trata de palabras: en el año 2005 se crea por una resolución del Ministerio del Interior un nuevo sistema de control denominado "Sistema Integrado de Captura Migratoria" y tres registros nacionales ${ }^{30}$, mediante disposición de la DNM, destinados a extender los controles estatales sobre el movimiento de personas (Novick, 2005).

En definitiva, desde este punto de vista, ahora la Argentina no estaría abierta a "todos aquellos que quieran habitar el suelo argentino", como lo expresa el preámbulo de la Constitución Nacional de 1853 (reformada en 1994), sino sólo a aquellos que tengan "leal voluntad de honesto arraigo".

[...] Es por eso que en esta coyuntura Argentina pretende enarbolar nuevamente su bandera de patria grande y abrir las puertas a todo aquél que con leal voluntad de honesto arraigo quiera residir en estas tierras. (Funcionario de la Dirección Nacional de Migraciones en el Seminario Migraciones y Derechos Humanos, Rosario, 2005).

[...] la República Argentina tiene los brazos abiertos para quienes quieran venir a habitar el suelo [argentino] con la única condición del respeto a las normas que se establecen en beneficio de todos. (Palabras de apertura en el Seminario Migraciones y Derechos Humanos, Rosario, 2005).

\section{Los inmigrantes y la sociedad de destino/recepción: el pluralismo cultural}

La intervención del Estado argentino en materia de migraciones, absorbida tradicionalmente por una visión restringida a la regulación y control de flujos poblacionales, se extiende ahora a otro de los ámbitos de las políticas migratorias: la incorporación de los migrantes en la sociedad de destino/recepción. En la actualidad, la ley de migraciones contempla específicamente cuestiones relativas a la inserción social, económica (especialmente laboral), política y cultural de los migrantes ${ }^{31}$. Es más, forma parte de los objetivos de la nueva ley: "Promover la integración en la sociedad argentina de las personas que hayan sido admitidas como residentes permanentes" (artículo3). Para Giustiniani, dirigente del Partido Socialista que impulsara la nueva ley siendo Presidente de la Comisión de Población y Recursos Humanos de la Honorable Cámara de Diputados de la Nación, "la política migratoria debe [...] fortalecer la integración del migrante en la estructura social del país" (Giustiniani, 2003: 23). Es destacable que para ello esta ley comprometa ahora a los poderes públicos a impulsar "el fortalecimiento del movimiento asociativo entre los inmigrantes" y apoyar "a los sindicatos, organizaciones empresariales y a las organizaciones no gubernamentales que, sin ánimo de lucro, favorezcan su integración social, prestándoles ayuda en la medida de sus posibilidades" (artículo 106). En términos generales, la preocupación estatal por la "regularización migratoria" adquiere también en este terreno un peso significativo. En 
el discurso oficial se muestra profundamente arraigada la idea que "la regularidad migratoria es realmente la base fundamental para conseguir la integración del migrante a la sociedad de recepción"32. Precisamente, uno de los objetivos del Programa Nacional de Normalización Documentaria Migratoria consiste en "la creación de nuevas políticas tendientes a la inserción e integración de la población inmigrante" (decreto 836/2004).

En relación a la inserción social y cultural de los inmigrantes, específicamente, el Estado ha adoptado el discurso pluralista o multiculturalista como parte constitutiva de su retórica de la inclusión. No obstante, a nuestro juicio, si bien el discurso oficial argentino habría incorporado en buena medida elementos de la ideología del pluralismo cultural, la formulación de sus proposiciones acerca de la inserción de los migrantes denota la vigencia de la ideología asimilación. Esto se manifiesta, inicialmente, en la utilización de la categoría "integración" para referirse al proceso de incorporación de los inmigrantes a la sociedad de recepción/destino y el sentido que le atribuye. En general, esta noción es usada como alternativa a la noción de asimilación y contrapuesta a la de segregación. Pero su uso conserva el sentido de "acomodación" y muestra que la relación entre los inmigrantes y la sociedad de destino/recepción es entendida desde la perspectiva del consenso o equilibrio social, esto es, la "integración" es conceptualizada como una necesidad y un fin u objetivo que procura el consenso y define el orden social.

Asimismo, el "modelo de integración" que se propone no logra trascender la perspectiva liberal sobre la diversidad cultural y, consecuentemente, no se compromete más allá de ciertas prácticas enmarcadas en el modelo de comprensión cultural (McCarthy, 1999), ya que supone una igualdad formal y se apoya en una visión de reciprocidad y consenso entre los distintos sectores y grupos sociales y étnicos a la vez que promueve un discurso de aceptación, tolerancia y respeto de las diferencias culturales próximo al "multiculturalismo pluralista" o alejado del "multiculturalismo crítico"; a nivel práctico, apuesta por una "mejora en la comunicación" de los diferentes sectores grupos étnicos y un cambio de actitudes para revertir los prejuicios, haciendo hincapié, en consecuencia, en programas de sensibilización y formación en relaciones humanas. Por ejemplo, se trata de favorecer medidas donde la interrelación entre los "locales" e "inmigrantes" se limita al "conocimiento y la valoración de las expresiones culturales, recreativas, sociales, económicas y religiosas de los inmigrantes" (artículo 14) y se deposita demasiada confianza en estrategias de difusión de información y cursos de formación para promover y lograr la inserción de los migrantes, cuando se trata más bien de metodologías complementarias que pueden servir para el inicio de cambios más significativos y profundos. Algunas indicaciones de carácter práctico como el ofrecimiento exclusivo de "cursos de idioma castellano en las escuelas e instituciones culturales extranjeras legalmente reconocidas" (artículo14) también se enmarcan en estrategias que responden a un modelo de integración monocultural o asimilacionista.

Una de las contradicciones más evidentes en este terreno consiste en declarar la importancia que reviste la aceptación de la diferencia cultural a la vez que se defiende en términos exclusivistas la identidad nacional: los inmigrantes tienen "la obligación de respetar la identidad cultural de los argentinos" (artículo 125). Esta visión supone, además, que las identidades en general son fijas o estáticas y que en la situación previa o posterior al contacto sociocultural la sociedad de destino/recepción es culturalmente 
homogénea, equiparando claramente "integración" a "asimilación". Asimismo, las estrategias de "integración" propuestas están destinadas a promover únicamente la inserción en la sociedad argentina de aquellas personas que sean admitidas por el Estado como "residentes permanentes" (artículo 3) y en el contexto de su comunidad de residencia (artículo 14). Esto implica, en primer lugar, que los "residentes temporarios" quedan excluidos de los "beneficios" de la integración: entre ellos se incluye una amplia franja de extranjeros que pueden ingresar al país bajo alguna de las siguientes subcategorías: trabajadores migrantes, rentistas, pensionados, inversionistas, científicos y personal especializado, deportistas y artistas, religiosos de "cultos reconocidos oficialmente", pacientes bajo tratamientos médicos, académicos, estudiantes, asilados y refugiados, ciudadanos nativos de Estados Parte del Mercosur, Chile y Bolivia, extranjeros que invoquen razones humanitarias y otros que ingresen al país por razones no contempladas anteriormente y sean consideradas de interés por el Ministerio del Interior y el Ministerio de Relaciones Exteriores, Comercio Internacional y Culto (artículo 23). Mas allá de que en la práctica las estrategias de incorporación no sólo tienen lugar a partir de la iniciativa del Estado, es interesante observar quiénes son contemplados en el proyecto de nación como potenciales sujetos a ser "integrados" y la concepción asimilacionista de "integración" que subyace a esta medida: los "integrables" serían sólo aquellos extranjeros que tengan interés en establecerse definitivamente en el país o, en otras palabras, aquellos que estén decididos a formar parte del "todo" nacional. Lo paradójico es que esto se sostenga en una ley que se fundamenta en la noción de "ciudadanía comunitaria". En este sentido, el Estado estaría contemplando los "espacios transnacionales", pero no estaría atendiendo a los "migrantes transnacionales", ignorando de esta manera las nuevas tendencias y formas que adquieren en la actualidad los flujos migratorios.

Esta articulación entre pluralismo cultural y asimilación de las políticas culturales propuestas en el campo de migraciones, nos llevan a sugerir que el pluralismo cultural adoptado operaría a manera de una "nueva ideología de la asimilación" ${ }^{3}$. Dicho de otro modo, bajo el régimen de hipervisibilidad étnica que se produce en la década de los noventa en la Argentina (Grimson, 2006) y frente a la pérdida de legitimidad de las políticas de asimilación, las políticas estatales se reconvertirían bajo la forma del pluralismo cultural, aunque con un marcado contenido asimilacionista. En el marco de esta "nueva ideología de la asimilación" se reconoce la sociedad como multicultural y multiétnica, se valora la contribución de los distintos grupos étnicos y migrantes al crecimiento y desarrollo del país, así como tomar conocimiento de ello, se promueve el respeto y tolerancia a la diversidad cultural para la disminución de la discriminación y los prejuicios, se reconocen derechos de igualdad formal, pero se mantiene inalterada la estructura de poder que (re)produce las condiciones materiales y simbólicas de dominación y exclusión social. En este contexto, es esperable que a los inmigrantes se los interpele no sólo ofreciéndoles integrarse en la cultura dominante transformándose en malas copias o mantener sus particularidades a costa de su marginación y exclusión social (Juliano, 1994), sino también invitándolos a conservar algunas de sus particularidades identitarias (en definitiva, aquellas que no amenacen la supuesta "unidad cultural") junto a oportunidades de ascenso social individual a cambio de ignorar o abandonar, parcial o totalmente, reclamos y luchas por proyectos de sociedad que comprometan la estabilidad o reproducción del sistema político, económico y cultural. 


\section{A modo de reflexión final}

Estos escenarios invitan a explorar más a fondo las contradicciones que se desarrollan en las relaciones estatales e intergubernamentales y las tensiones y articulaciones que se presentan en la conformación de las agendas nacional, regional e internacional. Por ahora, esta primera aproximación permite aventurar que las transformaciones acontecidas y en curso a nivel nacional en materia migratoria guardan una notable correspondencia con las agendas internacional y regional, promovida por algunas agencias internacionales ("globalización desde arriba"), a la vez que mantienen una vinculación con las demandas de los movimientos sociales y organizaciones de la sociedad civil ("globalización desde abajo"), en particular aquellas exigencias que se articulan con los lineamientos generales de las Naciones Unidas y la OIM. Ello, junto a las fuerzas sociales locales y frente a la retórica de la exclusión imperante en la década de los noventa, ha contribuido a conformar e instalar en el discurso oficial una retórica de la inclusión basada en los derechos humanos, la ciudadanía comunitaria y el pluralismo cultural. En este sentido, pese a que la nueva relación entre el Estado argentino, la migración y los migrantes inaugura una etapa inédita en materia de migraciones, la política migratoria actual se inscribe en una tendencia internacional y regional, esto es, reconocimiento formal de los derechos humanos, diferenciación entre comunitarios y extracomunitarios, introducción de medidas referidas a la integración de los migrantes y adopción del discurso pluralista, que no conlleva necesariamente una reformulación del vínculo entre "migración" y "desarrollo". Por tanto, resulta imprescindible discutir en qué medida la redefinición del orden migratorio internacional y la puesta en práctica de su agenda sin una radical transformación del modelo de desarrollo económico permite la formulación y concreción de un orden internacional alternativo.

\section{BIBLIOGRAFÍA}

BADARÓ Máximo (2006) La conciencia y la ley: la cuestión migratoria en las prácticas de agencias estatales y organismos no gubernamentales en la Ciudad de Buenos Aires, en Alejandro Grimson y Elizabeth Jelin comps., Migraciones regionales hacia la Argentina. Diferencia, desigualdad y derechos, Buenos Aires, Prometeo, pp. 207-235.

BENENCIA Roberto (2003) La inmigración limítrofe, en Fernando Devoto, Historia de la inmigración en la Argentina, Buenos Aires, Sudamericana, pp. 433-484.

CAGGIANO Sergio (2006) Fronteras de la ciudadanía. Inmigración y conflictos por derechos en Jujuy, en Alejandro Grimson y Elizabeth Jelin comps., Migraciones regionales hacia la Argentina. Diferencia, desigualdad y derechos, Buenos Aires, Prometeo, pp. 237-284.

CELS (1999) Inmigración, política estatal y vigencia de los derechos económicos, sociales y culturales de los inmigrantes y trabajadores migratorios peruanos y bolivianos en Argentina, Buenos Aires, Centro de Estudios Legales y Sociales. 
CERIANI Pablo (2004) Nueva Ley: un paso hacia una concepción distinta de la migración, en Rubén Giustiniani comp., Migración: un derecho humano, Buenos Aires, Prometeo, pp. 113-135.

COHEN Néstor y Carolina MERA comps. (2005) Relaciones interculturales: experiencias y representación social de los migrantes, Buenos Aires, Antropofagia.

CORREA Violeta (2004) La nueva ley de migraciones y la participación de las organizaciones de la sociedad civil, en Rubén Giustiniani comp. Migración: un derecho humano, Buenos Aires, Prometeo, pp. 173-177.

COURTIS Corina (2006) Hacia la derogación de la Ley Videla: la migración como tema de labor parlamentaria en la Argentina de la década de 1990, en Alejandro Grimson y Elizabeth Jelin comps. Migraciones regionales hacia la Argentina. Diferencia, desigualdad y derechos, Buenos Aires, Prometeo, pp. 169-205.

DEVOTO Fernando (2003) Historia de la inmigración en la Argentina, Buenos Aires, Sudamericana.

DOMENECH Eduardo (comp.) Migraciones contemporáneas y diversidad cultural en la Argentina, Córdoba, CEA-UNC.

GIUSTINIANI Rubén (2004) Fundamentos de la Ley, en Rubén Giustiniani comp. Migración: un derecho humano, Buenos Aires, Prometeo, pp. 19-42.

GRIMSON Alejandro (2006) Nuevas xenofobias, nuevas políticas étnicas en la Argentina, en Alejandro Grimson y Elizabeth Jelin comps. Migraciones regionales hacia la Argentina. Diferencia, desigualdad y derechos, Buenos Aires, Prometeo, pp. 69-97.

GRIMSON Alejandro y Elizabeth JELIN comps. (2006) Migraciones regionales hacia la Argentina: Diferencia, desigualdad y derechos, Buenos Aires, Prometeo.

JELIN Elizabeth (2006) Migraciones y derechos: instituciones y prácticas sociales en la construcción de la igualdad y la diferencia, en Alejandro Grimson y Elizabeth Jelin comps. Migraciones regionales hacia la Argentina. Diferencia, desigualdad y derechos, Buenos Aires, Prometeo, pp. 47-68.

JULIANO Dolores (1994) La construcción de la diferencia: los latinoamericanos, Papers, Barcelona, 43, pp. 23-32.

MÁRMORA Lelio (2003) Políticas migratorias consensuadas en América Latina, Estudios Migratorios Latinoamericanos, 17 (50), pp. 111-141.

MÁRMORA Lelio (2004) Las leyes de migraciones como contexto normativo (De la "Ley Videla" a la Ley de Migraciones 25.871), en Rubén Giustiniani comp. Migración: un derecho humano, Buenos Aires, Prometeo, pp. 59-65.

MATO Daniel (2001) Producción transnacional de representaciones sociales y transformaciones sociales en tiempos de globalización, en Daniel Mato comp. Estudios latinoamericanos sobre cultura y transformaciones sociales en tiempos de globalización, Buenos Aires, CLACSO, pp. 127-159.

McCARTHY Cameron (1999) Enfoques multiculturales de la desigualdad racial en Estados Unidos, en Mariano Enguita ed. Sociología de la Educación, Barcelona, Ariel, pp. 221-238.

NOVICK Susana (1997) Políticas migratorias en la Argentina, en Enrique Oteiza, Susana Novick y Roberto Aruj, Inmigración y discriminación. Políticas y discursos, Buenos Aires, Grupo Editor Universitario.

NOVICK Susana (2004) Una nueva ley para un nuevo modelo de desarrollo en un contexto de crisis y consenso, en Rubén Giustiniani comp. Migración: un derecho humano, Buenos Aires, Prometeo, pp. 67-85. 
NOVICK Susana (2005) La reciente política migratoria en el contexto del Mercosur, en Susana Novick, Alejandro Hener y Pablo Dalle, El proceso de integración Mercosur: de las políticas migratorias $y$ de seguridad a las trayectorias de los inmigrantes, Buenos Aires, Instituto Gino Germani de la Universidad de Buenos Aires, Documentos de Trabajo no 46, pp. 6-63.

PORTES Alejandro (2001) Debates y significación del transnacionalismo de los inmigrantes, Estudios Migratorios Latinoamericanos, 49, pp. 469-483.

SANTOS Boaventura de Sousa (2002) Hacia una concepción multicultural de los derechos humanos, en El Otro Derecho, ILSA, 28, pp. 59-84.

SASSEN Saskia (2001) ¿Perdiendo el control? La soberanía en la era de la globalización, Barcelona, Bellaterra.

SASSEN Saskia (2003) Los espectros de la globalización, Buenos Aires, Fondo de Cultura Económica.

SAYAD Abdelmalek (1998) A imigracão ou os paradoxos da alteridade, São Paulo, Editora da Universidade de São Paulo, 304 p.

STOLCKE Verena (1999) New Rhetorics of Exclusion in Europe, International Social Science Journal, no 159 , pp. 25-35.

STUHLDREHER Amalia (2006) La problemática de la migración en América Latina: ¿De enfoques intergubernamentales hacia la transnacionalización de la política migratoria?, en Ingrid Wehr ed. Un continente en movimiento: Migraciones en América Latina, Madrid / Frankfurt, Iberoamericana / Vervuert.

\section{NOTAS}

1. Por ejemplo, en el informe del Secretario General de Naciones Unidas del año 2002, titulado Strengthening of the United Nations: An Agenda for Further Change, se declara a la migración como una prioridad para la "comunidad internacional". Por otra parte, hay importantes excepciones como las Metas del Milenio del año 2000 donde no se contempla dentro de sus objetivos y metas el tema migratorio.

2. La noción de "agenda", de frecuente uso, tiene siempre un carácter prospectivo. Etimológicamente proviene del latín y hace referencia a "cosas que se han de hacer".

3. Este artículo ha tenido lugar en el marco de dos proyectos de investigación que cuentan con el apoyo económico de la Secretaría de Ciencia y Tecnología de la Universidad Nacional de Córdoba, Argentina.

4. Según la tipología propuesta por Portes (2003), las actividades transfronterizas de diferentes actores sociales pueden ser internacionales, multinacionales o transnacionales. Establece una distinción entre las actividades internacionales de los gobiernos y otras instituciones que se identifican con un Estado-nación particular, las iniciativas multinacionales de instituciones globales (como diversas agencias de Naciones Unidas y la Iglesia Católica) y las actividades transnacionales de las ONG y actores no corporativos provenientes de la sociedad civil, entre los cuales considera las asociaciones de migrantes transnacionales.

5. Entre los documentos oficiales se han considerado básicamente aquellos relacionados a la normativa migratoria, especialmente la nueva ley de migraciones (Ley № 25.871). Las intervenciones públicas de los funcionarios fueron tomadas del Seminario sobre Migraciones y Derechos Humanos y del Seminario sobre Migraciones y Ciudadanía, organizados por la Delegación Rosario de la Dirección Nacional de Migraciones (DNM), dependiente del Ministerio del Interior, en el año 2005 y 2006 respectivamente. 
6. Para la elaboración de este trabajo se ha recurrido a fundamentalmente a diversos documentos internacionales, regionales y nacionales sobre migraciones y a intervenciones públicas de funcionarios políticos del gobierno argentino realizadas en eventos organizados recientemente por la Dirección Nacional de Migraciones del Ministerio del Interior.

7. La política migratoria de los Estados Unidos sigue expresamente los lineamientos de su política de "seguridad nacional". Especialmente después del denominado 11/s la política migratoria es considerada como un instrumento para "combatir el terrorismo". Así lo expresa con claridad -sin necesidad de ningún tipo de eufemismo- una de las directivas del presidente norteamericano George W. Bush titulada Combatting Terrorism Through Immigration Policies (Homeland Security Presidential Directive, 29 de octubre de 2001).

8. Los Estados involucrados en la CRM, originada en el año 1996, son Belice, Canadá, Costa Rica, El Salvador, Honduras, Guatemala, México, Nicaragua, Panamá y Estados Unidos. La República Dominicana se incorporó en 1999. Argentina, Colombia, Ecuador, Jamaica y Perú participan como observadores.

9. La Conferencia Sudamericana sobre Migraciones se ha desarrollado hasta ahora en Buenos Aires (2000), Santiago de Chile (2001), Quito (2002), Montevideo (2003), La Paz (2004) y Asunción (2006). La VII Conferencia está prevista en Caracas. Los Estados participantes son Argentina, Bolivia, Brasil, Colombia, Chile, Ecuador, Paraguay, Perú, Uruguay y Venezuela. En la II Conferencia participó también Guyana y en la VI Suriname.

10. Para un análisis de la cuestión migratoria en estos procesos de integración subregional y en los foros consultivos regionales, véase Mármora (2003), Novick (2005) y Stuhldreher (2006).

11. Surge así en el año 2002 lo que posteriormente se conocerá como el Encuentro Alternativo Sudamericano de Migraciones, integrado por numerosas organizaciones regionales y nacionales de la sociedad civil. Es considerado un espacio de diálogo, articulación y fortalecimiento que actúa en representación de sectores de la sociedad civil en América del Sur, comprometido con la defensa de los derechos de los migrantes, refugiados, desplazados y sus familias.

12. En el marco del Mercosur, con el reemplazo del SGT № 11 por el Subgrupo № 10 de Asuntos Laborales, Empleo y Seguridad Social (SGT10), la movilidad de trabajadores cambió de enfoque al dejar de ser tratada como "libre circulación de mano de obra" y ser considerada en términos de “migraciones laborales”. Véase Gurrieri (2005); Mármora (2003); Novick (2005); Stuhldreher (2006).

13. Por ejemplo, los grandes ejes temáticos del Seminario sobre Migración Internacional en las Américas fueron: tendencias y patrones migratorios en las Américas; relaciones entre la migración y el desarrollo; gobernabilidad de la migración y diplomacia multilateral; importancia económica y social de la migración; derechos humanos de los migrantes. Más recientemente, el documento la CEPAL titulado "Migración internacional, derechos humanos y desarrollo en América Latina y el Caribe", publicado a comienzos de 2006 antes de la VI Conferencia, presenta sus conclusiones en torno a "migración y derechos humanos de los migrantes", "migración y desarrollo" y "gobernabilidad de la migración internacional".

14. La Mesa de organizaciones en defensa de los derechos de los inmigrantes estuvo integrada originariamente por el Centro de Estudios Legales y Sociales (CELS), la Asamblea Permanente por los Derechos Humanos (APDH), el Movimiento Ecuménico por los Derechos Humanos (MEDH), el Servicio de Paz y Justicia (SERPAJ), la Fundación de la de la Comisión Católica de Migraciones (FCCAM), el Servicio Ecuménico de apoyo y orientación a inmigrantes y refugiados (CAREF) y el Departamento de Migraciones de la Confederación de Trabajadores Argentinos (CTA) (Correa, 2004).

15. También es necesario señalar que, a excepción de algunos casos, la gran mayoría de los actores sociales consultados durante la elaboración de la nueva ley se concentraron básicamente en Buenos Aires, reproduciendo la relación centro-periferia en el ámbito local. 
16. Véase Courtis (2006) para un análisis de los proyectos de ley que proponían la derogación de la Ley Videla y la creación de una nueva ley migratoria; Badaró (2006) para un examen de las modalidades que obtuvo el tratamiento de las migraciones de parte de los organismos estatales y las organizaciones no gubernamentales dedicados a la defensa de los derechos de los inmigrantes en la ciudad de Buenos Aires; también Caggiano (2006) sobre las connotaciones y disputas que despierta la nueva ley de migraciones en distintas jurisdicciones del Estado.

17. La noción de inmigrante, definida por las élites argentinas, tuvo desde su momento fundacional una connotación positiva, aunque fuera restringida progresivamente a su carácter europeo y agrario (Devoto, 2003: 40). Esta visión positiva de la inmigración estuvo asociada a la imagen de los inmigrantes como "agentes de civilización" y "fuerza de trabajo". Esto ocurre en un período histórico caracterizado por un desarrollo capitalista dependiente basado en la afluencia de capital y mano de obra extrajera, sostenido por una estrategia agroexportadora, y propicio para la sanción de la Ley de Inmigración de 1876 conocida como Ley Avellaneda, a través de la cual se canalizarán el flujo migratorio hacia la Argentina y el proceso colonizador (Novick, 1997: 91-92). Con posterioridad, como dice Devoto, los inmigrantes dejaron de ser "laboriosos" para volverse "potencialmente peligrosos". A principios del siglo XX, con el crecimiento de la participación de los inmigrantes en la formación de asociaciones obreras y movimientos políticos socialistas y anarquistas, la figura del inmigrante se torna para las clases dirigentes una amenaza al orden y cohesión sociales. Con este panorama se relaciona la adopción de normas restrictivas y represivas como la Ley de Residencia de 1902, la Ley de Defensa Social de 1910 y el Decreto-ley de 1923. En este contexto, para los inmigrantes que fueron expulsados del país por motivos políticos a principios de siglo y para "potenciales subversivos" se reservaba el rótulo de "extranjero" (Devoto, 2003: 37). El carácter autoritario y represivo de estas leyes se actualizará a partir de la década de los sesenta durante la dictadura de Onganía y con la última dictadura militar (1976-1983), cuando se institucionaliza la doctrina de seguridad nacional con la Ley General de Migraciones y Fomento de la Inmigración (Ley 22 439), conocida también como Ley Videla.

18. De acuerdo a estas imágenes de aceptación o rechazo se han construido tanto en el discurso académico como político categorías como "inmigrantes deseables" e "inmigrantes indeseables" respectivamente.

19. Para una revisión de la inmigración limítrofe en la Argentina, véase Benencia (2003). Para recientes trabajos sobre migraciones contemporáneas en la Argentina, véanse las compilaciones de Cohen y Mera (2005), Domenech (2005) y Grimson y Jelin (2006).

20. Véase Stolcke (1999) para un análisis acerca de la forma que adquiere la "retórica de la exclusión" en algunos países europeos como Francia y Gran Bretaña: el fundamentalismo cultural.

21. La aclaración "al menos abiertamente", se debe a que ciertos argumentos que suelen utilizarse en contra de la inmigración, como la amenaza al trabajo de los "nativos", aparecen en el discurso presidencial ofrecido durante la inauguración del Programa Nacional de Normalización Documentaria Migratoria hecha en diciembre de 2005: "es decir, todo se deba hacer tal cual marca la ley, pero la ley con el sentido de integrar, la ley con el sentido de dar posibilidades, la ley que tenga en el lugar que corresponde al ser humano, la ley que evite el abuso, que valore el trabajo del que viene, la ley que permita garantizar ese trabajo del que viene pero también que no devalúe el trabajo del que está en el país" (Discurso presidencial en el acto de presentación del Plan Nacional de Normalización Migratoria, Salón Blanco de la Casa Rosada, $14 / 12 / 2005$, énfasis propio).

22. A pesar de ello, podrían señalarse algunas contradicciones cuando se intenta conciliar la noción de migración como derecho humano y la visión de la migración como aporte o contribución fundada en una lógica de costo/beneficio.

23. Tampoco se puede reducir la perspectiva de los derechos humanos a una sola corriente ideológico-política. Según Santos (2002) los derechos humanos pueden ser utilizados como un 
instrumento hegemónico como contrahegemónico. Por tanto, es necesario precisar las condiciones bajo las cuales los derechos humanos permiten una construcción contrahegemónica, la cual debe adoptar la forma de un "cosmopolitismo subalterno" para el autor.

24. Esta situación llevó a que organismos representantes de países vecinos reclamaran, aunque de manera aislada, ante el Estado provincial la revisión de estas medidas. Por ejemplo, la República del Perú, a través de su consulado, manifestó, amparado en el convenio migratorio celebrado en 1999, "su preocupación sobre la problemática que atraviesan diversos niños peruanos [especialmente aquellos en una situación migratoria irregular] respecto a la accesibilidad al Sistema Educativo Provincial y a la obtención de la documentación que certifique sus estudios en nuestro país". El Ministerio de Educación resolvió “disponer que los alumnos de nacionalidad peruana con documentación de origen en regla poseerán pleno derecho de ingresar y egresar del Sistema Educativo Provincial como también de obtener las certificaciones y titulaciones en igualdad de condiciones con sus pares de nacionalidad argentina" (Resolución 1550/02).

25. Esta observación también es válida para aquellos organismos internacionales, asociaciones de inmigrantes u organizaciones de la sociedad civil comprometidas con los derechos humanos que pretenden legitimar la presencia/ausencia del migrante a través de la contribución, los beneficios o las ventajas que traen aparejadas las migraciones.

26. En el mes de febrero de 2004, por disposición de la Dirección Nacional de Migraciones, se suspenden las expulsiones de inmigrantes de países limítrofes que se encuentran en situación administrativa irregular.

27. Véase http://www.patriagrande.gov.ar. Nótese la similitud de estos argumentos con las afirmaciones que esgrimía un fiel representante del pensamiento neoconservador y neoliberal en la Argentina, el periodista Daniel Hadad, en la columna editorial del cuarto número de la revista La Primera de la Semana publicada en el año 2000: "Los inmigrantes indocumentados: Sólo consiguen emplearse en la economía informal, deprimiendo los salarios. Utilizan el sistema de salud que pagamos todos. Lo mismo hacen con la educación pública. Según estadísticas oficiales, cometen más delitos que el promedio de la población, y en algunos casos lo hacen para quedarse definitivamente en el país. Todo esto cuesta dinero. Y la Argentina dejó de ser hace mucho tiempo el hermano mayor, rico y poderoso que podía subsidiar a su familia desgraciada..." (extraído de Jelin, 2006: 60).

28. Por estas razones sería un error pensar que ahora la inmigración limítrofe, la cual fue objetada a lo largo de más de un siglo de vida política en el país, se convierte repentinamente en una "inmigración deseable" para el Estado.

29. Si bien representó un cambio en relación a la tradicional unilateralidad de las políticas migratorias, estos convenios se focalizaron casi con exclusividad en un aspecto de la problemática migratoria como es la regulación de la actividad laboral de los migrantes y no plantearon políticas de mayor alcance. Respecto al convenio argentino-boliviano, a pesar que eliminó ciertos elementos restrictivos de la ley migratoria vigente en aquel momento, permitiendo por ejemplo el acceso a la educación pública para los hijos de los migrantes en condición irregular (artículo 13), se concentró fundamentalmente en la integración económica del migrante boliviano en relación formal de dependencia o autónomo (artículo 1). Véase Sayad (1998) para una crítica a los acuerdos migratorios celebrados entre Estados reducidos a convenios laborales.

30. Los registros nacionales son los siguientes: Registro Nacional de Admisión de Extranjeros, Registro Nacional de Aptitud Migratoria y Registro Nacional de Ingreso y Egreso de Personas al Territorio Nacional (Disposición 15440/05, Disposición 15441/05 y Disposición 15442/05).

31. Es importante destacar que en la Argentina el debate en torno a la integración de los inmigrantes no es reciente. Se remonta en Argentina a fines del siglo XIX y comienzos del XX. 
32. El uso de la noción de "integración", aunque está extendido, no deja de ser problemático. En la literatura especializada aparece utilizada, en ocasiones, como contrapuesta a la noción de asimilación, ya que en principio no supone el abandono de los principales rasgos identitarios y culturales de los grupos étnicos. En este sentido, la "integración" también es considerada como un modelo de gestión de la diversidad alternativo a la asimilación. En otros lugares, el concepto es utilizado para denominar distintas formas de inserción asociadas a los modelos de asimilación, fusión o pluralismo cultural. Sea cual fuere el significado que se le asigne, en muchos casos la "integración" conserva el sentido de "acomodación" y no contempla la estructura de poder en la que se produce. Véase Grimson (2002) para un análisis de la noción de "integración” en el contexto de las "políticas de integración" en el Cono Sur.

33. Además, las tensiones o contradicciones entre estos modelos de integración serían salvadas, en parte, con el paso de políticas asimilacionistas a pluralistas siempre dentro de los límites de la tradición liberal.

\section{RESÚMENES}

En este artículo, en primer lugar, se describe en términos generales la emergencia de una nueva agenda política internacional sobre migraciones y su desarrollo en el ámbito de la región sudamericana, mostrando algunos de los cambios que se estarían produciendo a partir de la intervención de actores políticos que desarrollan actividades internacionales, multinacionales y transnacionales. En segundo lugar, se analiza el caso argentino, indagando particularmente las recientes transformaciones políticas en materia migratoria. Se indica que la Argentina constituye un caso que habilita la discusión acerca de la internacionalización de la política migratoria. En este sentido, se examina el giro que ha tenido el discurso oficial sobre migraciones al adoptar una retórica de la inclusión, basada en la perspectiva de los derechos humanos, la ciudadanía comunitaria y el pluralismo cultural, frente a la retórica de la exclusión de la década de los noventa.

L'agenda politique sur les migrations en Amérique du Sud : le cas de l'Argentine. En premier lieu cet article décrit, de façon générale, l'émergence d'un nouvel agenda politique international sur les migrations et son développement dans l'espace sud-américain. Il décrit certains des changements qui seraient en cours, entraînés par l'intervention d'acteurs politiques qui développent des activités internationales, multinationales et transnationales. Une attention particulière est apportée au cas argentin, observant les dernières transformations politiques en matière migratoire. Ce pays, vivant une réalité migratoire fort différente de celles d'autres pays récepteurs ou celles des sociétés capitalistes avancées, demeure un cas qui permet de réfléchir sur l'internationalisation de la politique migratoire. Dans ce sens, les changements du discours officiel sur migrations sont examinés. L'Argentine adopte aujourd'hui une rhétorique de l'inclusion, fondée sur la perspective des droits de l'homme, la citoyenneté communautaire et le pluralisme culturel, s'opposant à la rhétorique de l'exclusion de la décennie quatre-vingt-dix.

The Political Agenda on Migration in South America: the Case of Argentina. Firstly, the article describes the emergence of a new international political agenda on migration and its development in the South American region. It shows the kind of transformations produced by political actors when performing international, multinational, and transnational activities. Secondly, the essay analyses the Argentinean case and its recent political changes on migration. 
In this sense Argentina's case is relevant because it rises the question about the internationalization of migratory policy. Particularly, the article examines the metamorphosis in the state discourse from a rhetoric of exclusion during the 1990's to a rhetoric of inclusion, based on the perspective of human rights, communitarian citizenship, and cultural pluralism.

\section{ÍNDICE}

Mots-clés: intégration, relations internationales, politiques migratoires

Índice geográfico: Argentine

\section{AUTOR}

\section{EDUARDO E. DOMENECH}

Docente-investigador del Centro de Estudios Avanzados de la Universidad Nacional de Córdoba, Argentina, donde co-coordina el Programa Multiculturalismo, Migraciones y Desigualdad en América Latina. Miembro del Grupo de Trabajo "Migración y Cultura" del Consejo Latinoamericano de Ciencias Sociales (CLACSO). E-mail eduardo.domenech@gmail.com 